\title{
Numerical Analysis of the Influence of Rotor Wake on Hub Drag for a Coaxial Rigid Rotor
}

\author{
Chang Wang ${ }^{\mathrm{a}}$, Minqi Huang ${ }^{\mathrm{b},{ }^{*}}$, Min Tang $^{\mathrm{c}}$ and Long He ${ }^{\mathrm{d}}$ \\ China Aerodynamics Research and Development Center, Mianyang, China \\ arotor101@foxmail.com, bhmq1s@163.com, ctangmin@outlook.com, dhelong6789@qq.com
}

Keywords: Coaxial rigid rotor, ABC rotor, Hub drag, High speed helicopter, High speed rotorcraft.

\begin{abstract}
Hub system of coaxial rigid rotor has a significant contribution to the total vehicle parasite drag. Prior efforts have explored various faring designs to reduce flow separation and interference drag between each components of hub system. The aerodynamic interference physics of rotor wake on the hub fairing system components is still need to be resolved to examine its practicability. A numerical investigation was carried out to predict the influence of rotor wake on hub drag for a coaxial rigid rotor. The investigation was based on the solution of RANS equations in three dimensions using unstructured grids and main rotor modelled by an actuator disc. Results are presented for baseline configuration and optimized lower drag configuration under various forward flight velocities. The analysis shows that the presence of rotor wake has remarkable interference on hub drag, the swirl and downwash component of rotor wake have significant interference effect on each parts of hub fairing system. With the increase of wind speed, interference effects have been altered by the movement of rotor wake. The additional rotor wake remarkably increases the hub system drag in low speed range, and makes the hub system drag slightly reduction at higher speed. The drag of optimized model is still lower than base model in the interference of rotor wake, reveals that the optimized technique which is to reshape the shaft fairing and pylon is effective in the presence of rotor wake.
\end{abstract}

\section{Introduction and Objectives}

Achieving high speed flight as fixed plane is one of the major development orientations for the future rotorcraft. The demonstrations developed by Sikorsky Aircraft Corporation, including XH-59A, X-2 have shown the benefit of the Advancing Blade Concept (ABC) rotor system to enhance the maximum forward speed range compared to a conventional helicopter [1,4]. The Advancing Blade Concept system consisted of two rigid, contra-rotating rotors which made use of the aerodynamic lift of the advancing blades. At high speeds, the retreating blades were offloaded, as most of the load was supported by the advancing blades of both rotors and the penalty due to stall of the retreating blade was thus eliminated [1-5]. However, implementing ABC rotor that efficiently enables such high speed in long range cruise will require substantial progress in multiple disciplines, including advances in hub drag reduction.

The hub of a coaxial rigid rotor is a major contributor to parasitic drag on forward performance. It has been found to contribute approximately $50 \%$ of the vehicle parasite drag as in the case with the XH-59A [6]. Fig1 shows the X-2 technology demonstrator and its hub fairing system, since there are many non-streamlined mechanical components in hub and swash plate, therefore the ellipse fairing installed outside of the hub, and pylon installed outside of the swash plate of the lower rotor. However, the effect of the hub fairing did not achieve the desired objectives due to the additional interference drag attributed from the separation wake originated from the shaft and pylon.

In the past two decades, many researches have been done to reduce the hub drag for coaxial rigid rotor by optimizing the hub fairing configurations, most of those work has focused on eliminating the interference drag between the hub and shaft and pylon.

A wind tunnel test was performed by Sikorsky in the late 1970's[7], it has found that aerodynamic interaction between the hub fairing/shaft/pylon are the fundamental factors that determine the drag 
level of similar hub fairing designs. Recently, CFD simulation was applied to explore various fairing designs, acceptable correlation for experiment was achieved [6], Furthermore, larger shaft fairing has been shown reduce the drag on the top and bottom hub fairings. Recent experimental work at CARDC has demonstrated that longer shaft fairing and pylon can alleviate pressure gradient and make the separation point move backward, reduce the disturbance suffered by the hub fairing, the optimized configuration has a drag reduction of more than $43 \%$ relative to the baseline [8].

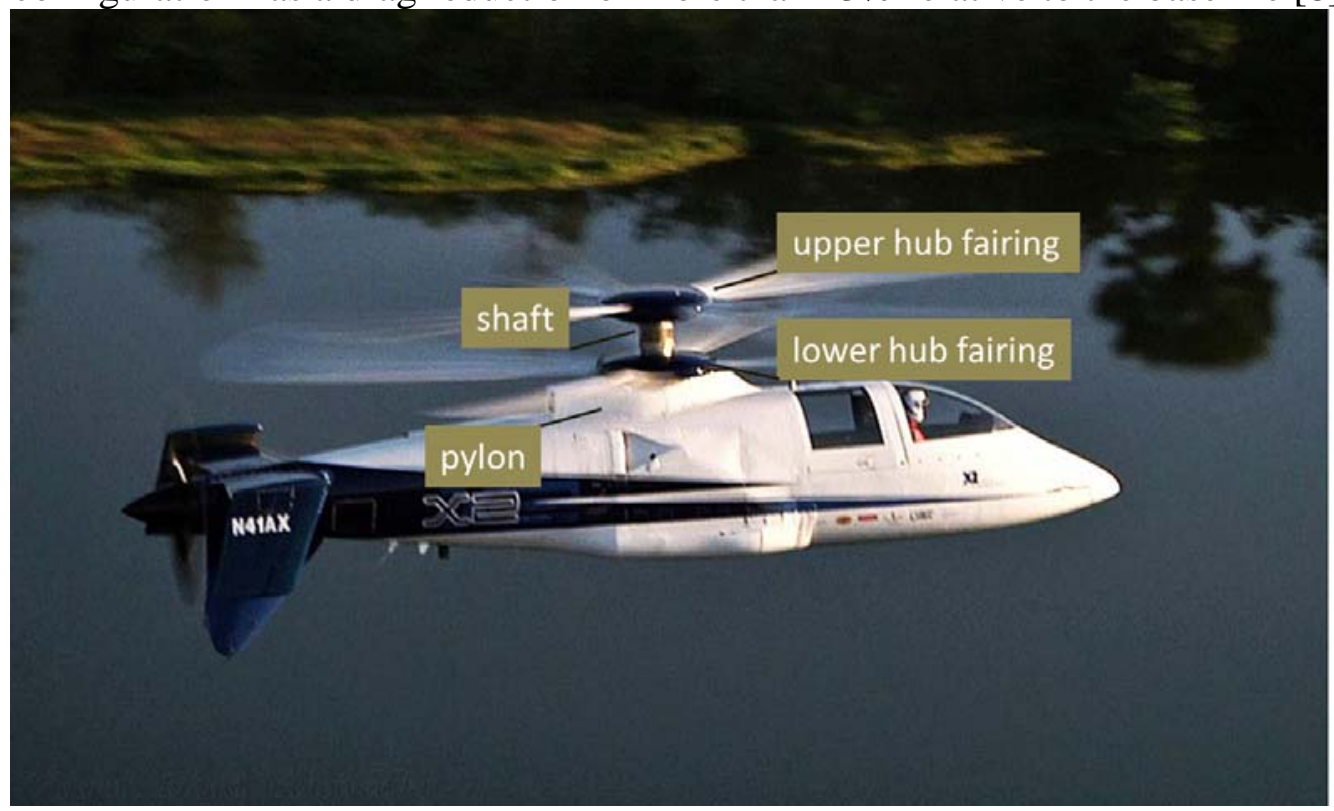

Figure 1 Sikorsky's X2 Technology ${ }^{\mathrm{TM}}$ Demonstrator.

Except the reshape design method, passive and active flow control means have been employed. The experimental investigation of passive and active flow control for a state-of-the-art low-drag coaxial hub design of the X2TD showed that the steady blowing from the rotor shaft fairing can reduced drag $4 \%[9]$.

Despite the means of reducing hub drag has been widely studied for coaxial rigid rotor system, there is an important issue still unresolved. Most of previous researches ignore the interference effect of rotor wake on hub fairing system. It is need to know the aerodynamic interference between the rotor wake and hub fairing system components, especially whether the swirl velocity of rotor wake can increase the drag of longer shaft fairing and pylon, and thus offset its drag reduction effect.

In this paper, the main objectives are to: quantify and reveal the interference effect of rotor wake on hub fairing and shaft fairing and pylon, confirm whether the larger shaft fairing and pylon is still lower drag in the ambiance of rotor wake. Therefore, a CFD analysis was applied to compare the base model's and the optimized model's drag and flow dynamics characteristics with rotor wake disturbance, the models are equal to that was obtained in the previous experimental researches [8].

\section{Computational Methods}

An unstructured flow solvers, CD-adapco STAR-CCM+, has been used in this work. Actuator disc model were used for rotors wake simulations, and a trimmed mesh is adopted with an adequately fine prism layer for appropriate near-wall modeling (Fig. 2). Turbulence effects were accounted for by the two-equation Wilcox's k-w model. All computations were performed on the computational cluster of shanghai supercomputer center.

Two different configurations of hub fairing system were utilized in this research, a baseline model and an optimized model (Fig. 3). The optimized model showed 43\% drag reduction contrast to the baseline model in the previous wind tunnel experimental performed by CARDC[3]. The diameter of hub fairing is 55 centimeters that correspond as a $2 \mathrm{~m}$ diameter rotor, this size is equal to the test model of future wind tunnel test. The rotor is a four-bladed coaxial rigid type, and its major parameters are shown in Table 1. For comparison the blade wake impact effect, both of the isolate 
hub system and the blade-hub combination configuration are simulated. In actuator disc computation, the collective and cycle pitch angle were adjusted to make the steady thrust coefficient CT $=0.012$ at each free stream velocity with hub moment set to zero.

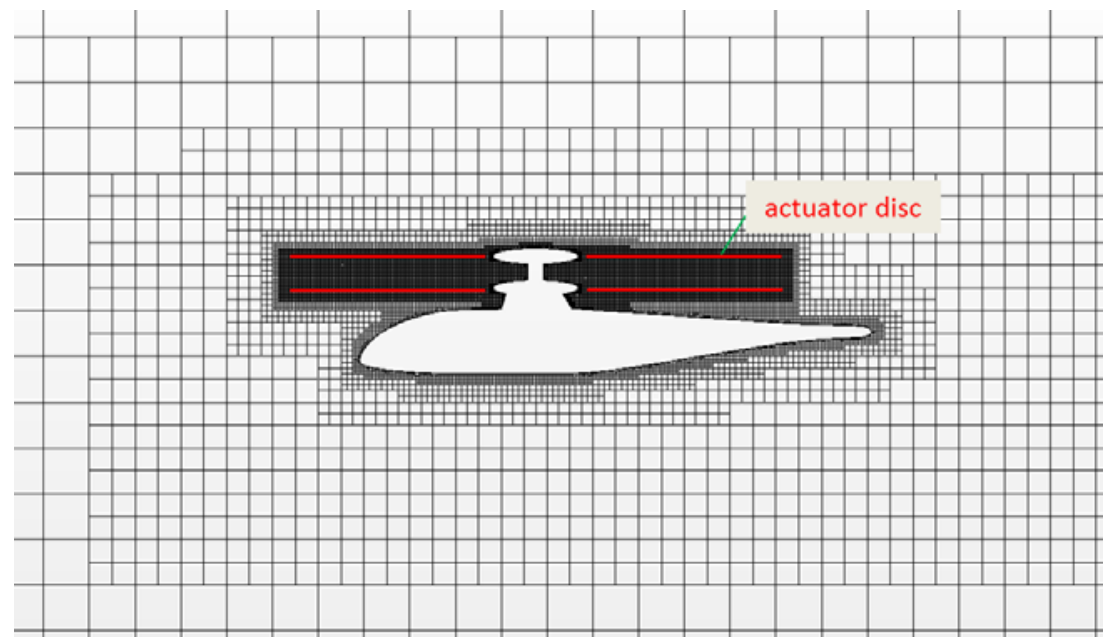

Fig.2.Front view of the middle section of volume grid.

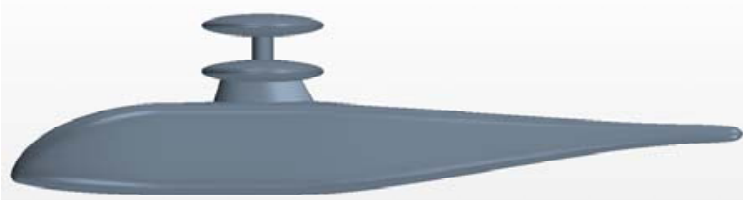

a)

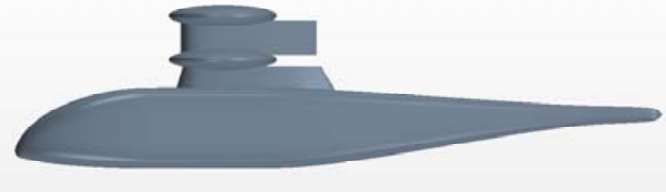

b)

Fig.3 Geometries of a) baseline model and b) optimized model.

Table 1. Major parameters of the coaxial rotor for computation

\begin{tabular}{|c|c|}
\hline Blade Chord: $\mathrm{c}$ & $55 \mathrm{~mm}$ \\
\hline Rotor Diameter: $\mathrm{R}$ & $1 \mathrm{~m}$ \\
\hline Airfoil & NACA 0015 \\
\hline Root Cutout & $0.2 \mathrm{R}$ \\
\hline Built-in Twist & $-12^{\circ}$ \\
\hline CCW \\
\hline Rotation Direction of Upper Rotor & CW \\
\hline Rotation Direction of Lower Rotor & \\
\hline
\end{tabular}

\section{Results and Discussion}

The parasite drag area Cxs, is used as an indicator to expressed the change in drag of each shape associate with different free stream velocity. The overall drag areas of hub system (the ensemble of hub fairing, shaft and pylon) for each configuration as a function of the free stream velocity are illustrated in fig. 4. It should be note that, for the isolate hub cases, the effect of Reynolds numbers resulted in somewhat variations of the hub system drag areas as the speed increased. While for the blade wake addition cases, there are larger fluctuations on the changing curves of the hub system overall drag area corresponding to speed, in terms of both amplitudes and trends. The presence of the rotor wake increases the hub system drag in low speed range remarkably. However, the increases in the overall drag are declining with the speed increase, even a slightly lower hub system drag with the disturbance of rotor wake starts at $90 \mathrm{~m} / \mathrm{s}$ speed. In particular, the drag of optimized model is still lower than base model when impacted by the disturbance from rotor wake, reveals the optimize technique that reshape the shaft fairing and pylon is effective in the presence of rotor wake. 


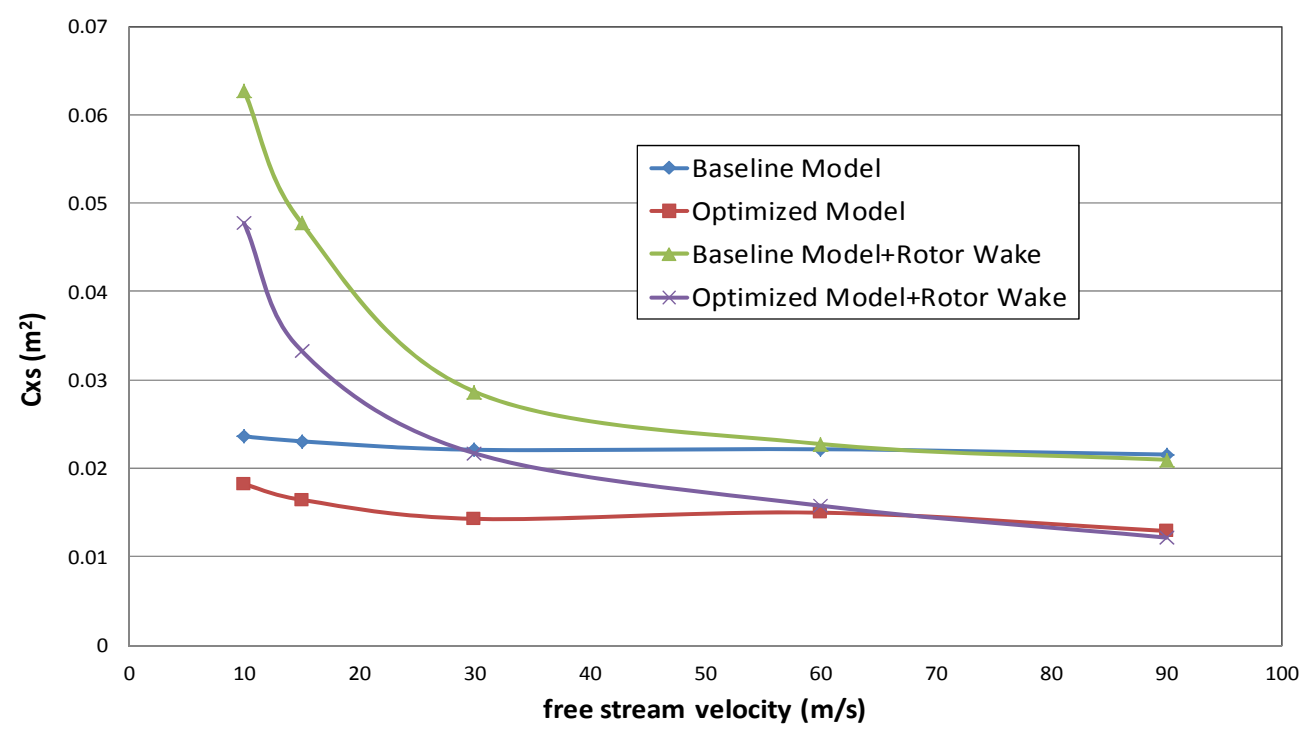

Fig. 4 Overall drags of hub system scaled by dynamic pressure Vs free stream speed for different configurations.

Hub system drag breakdown patterns given in Fig. 5 for the three representative free stream speeds explain how the drag of each component evolved as the speed increased. At the $10 \mathrm{~m} / \mathrm{s}$ condition, the additions of the blade wake add a fairly remarkable increment in drag over each components of hub system, led to higher overall drag levels for both the baseline and optimized configuration. While with the wind velocities increase, the effect of blade wake didn't propel the drag growth of all the components. At the $60 \mathrm{~m} / \mathrm{s}$ condition, the drag distribution tendency of each component in the Baseline configuration isn't consistent in optimized configuration. It is also of interest to note, for the blade wake case, reduction in drag for down hub and pylon are found in both configurations, the drag of shaft of baseline configuration is decreased but it is similarly with optimized configuration, are accompanied by increases for up hub, and overall drag. At the $90 \mathrm{~m} / \mathrm{s}$ condition, the drag distributions tendencies among each component are similar with $60 \mathrm{~m} / \mathrm{s}$ condition, and demonstrate slightly reduced overall hub drag compared to isolated configuration.

The comparisons of flow streamline on the longitudinal cross section of baseline model for isolate and combine configuration at $10 \mathrm{~m} / \mathrm{s}$ has been shown in Fig.6. It can be seen that the downwash occupies a dominant component of rotor wake in low speed flight, resulting in a move upward of the stagnation point near the leading edge of hub fairing, and then increase stagnation pressure and greater adverse pressure gradient. These factors introduce a sharp increase in the drag of hub fairing, particularly for the upper hub fairing.

In Fig.7, the comparison of flow streamline is shown on the horizontal cross section of shaft fairing of optimized model with and without the influence of rotor wake. As expected, without the influence of the rotor wake, the flow pattern in middle section can be considered to be symmetric flow. It experiences increased lateral flow caused by swirl component of rotor wake when influenced by rotor wake, which brings an angle of attack enhancement for shaft fairing and leads asymmetric flow pattern. The stagnation pressure of shaft fairing is also increased with the presence of swirl rotor wake. These effects lead to an increase in flow separation, resulting in a larger drag for shaft fairing and pylon. As known in previous study [7,8], the shaft and pylon is not a major contributor to the overall drag, but it has a significant impact on the drag of the hub fairing since their interaction with the shaft and pylon and hub. Furthermore, with the increasing separation wake from shaft and pylon, the hub fairing drag will produce an increase due to the flow disturbance. 


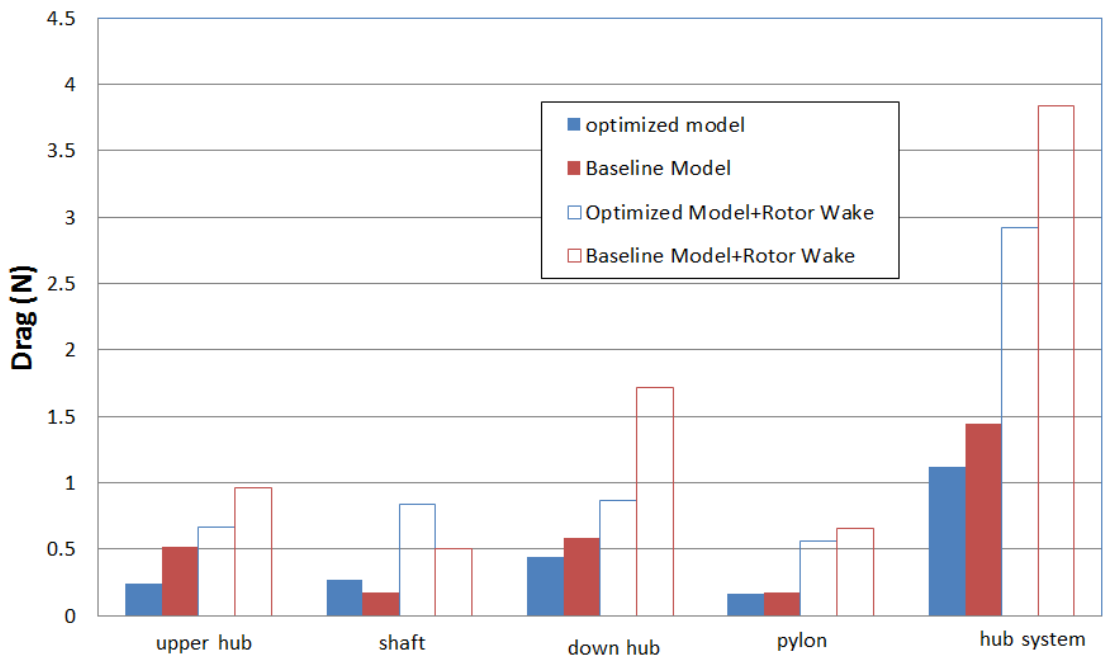

a) $10 \mathrm{~m} / \mathrm{s}$

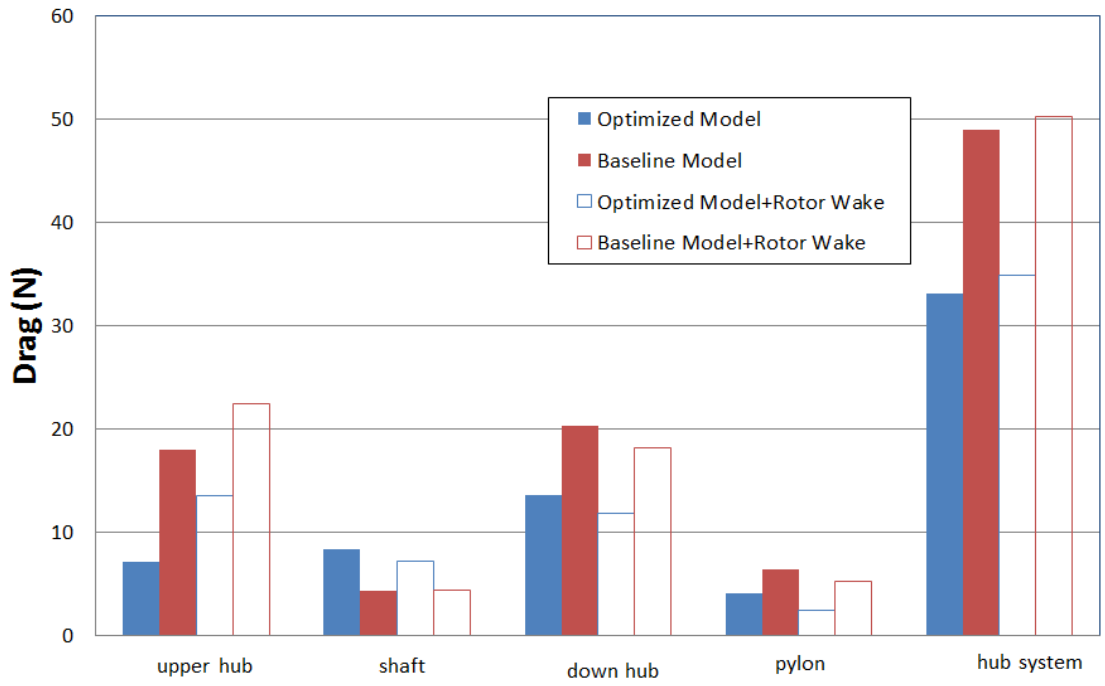

b) $60 \mathrm{~m} / \mathrm{s}$

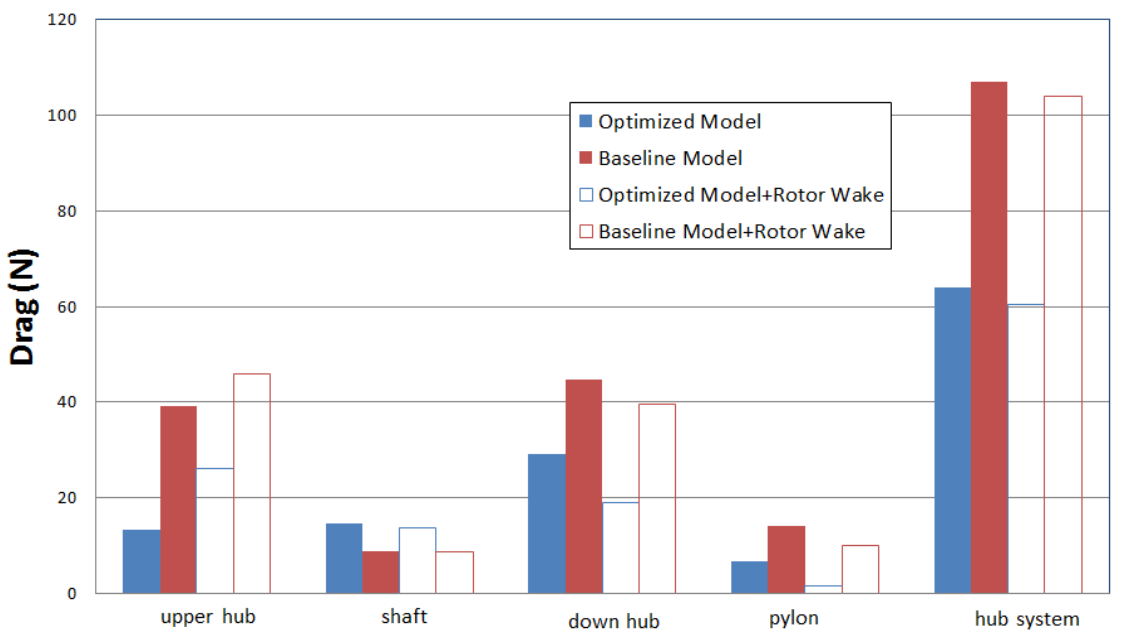

c) $90 \mathrm{~m} / \mathrm{s}$

Fig.5 Drag breakdown patterns. 


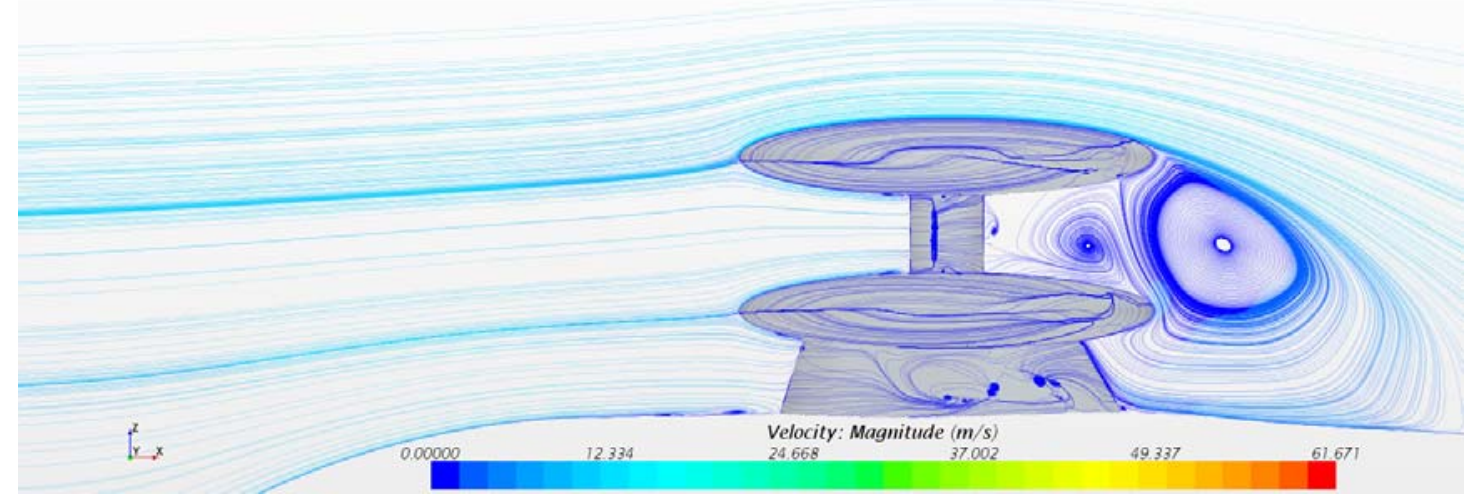

a)

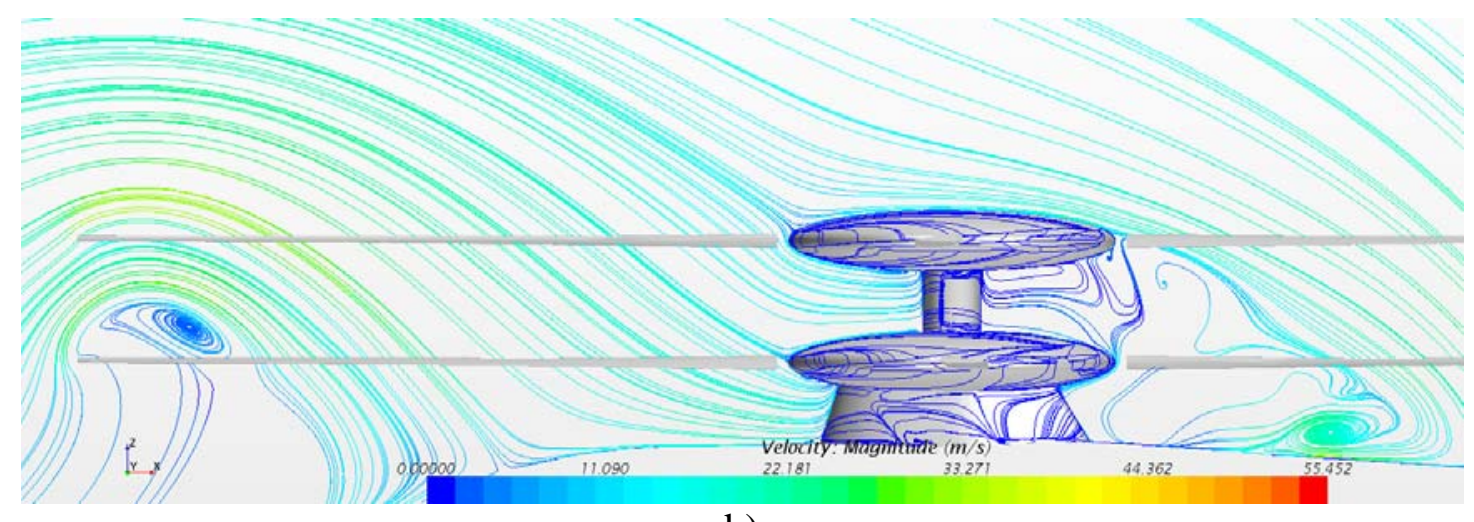

b)

Fig.6 Comparison of flow streamline on the longitudinal cross section of baseline model at $10 \mathrm{~m} / \mathrm{s}$ speed. without the influence of rotor wake a) and with the influence of rotor wake b).

The flow streamline on the longitudinal cross section of baseline model with the influence of rotor wake at $90 \mathrm{~m} / \mathrm{s}$ speed has been shown in Fig.8. With the increase of free stream velocity, there appears an obvious upward and backward movement for the rotor wake, while the strength of downwash is reduced, that lead the improvement of hub fairing drag is relatively decreased.

Fig.9 show the flow streamline on the horizontal cross section of shaft fairing and pylon of optimized model affected by the rotor wake. Since the affected area is traverse to the downstream of shaft fairing and pylon, the influence effects on the stagnation pressure and angle of attack become very weak, and a mitigation of flow separation on the horizontal cross-section of shaft fairing and pylon can be obtained. Affected by this, the shaft fairing and pylon's drag decreased significantly. Consequently, the interference drag suffered by lower hub fairing are experienced a significant decline.

Based on the forgoing results, the downwash component of rotor wake mainly affect hub fairing, swirl mainly effect shaft and pylon. As the wind speed increases, the rotor wake moves upward and backward with the decrease of downwash component. Under the low wind speed range, each components of hub system experience growth of stagnation pressure and adverse pressure gradient increasing, resulting in increased drag of each components and interference drag. As the wind velocity increase, on the one hand, the down wash component weakened, resulting in a relatively decrease in the amount of growth of hub fairing drag; the rotor wake moves upward and backward, the swirl component of rotor wake mainly mitigate the flow separation on the downstream of horizontal cross-section of shaft fairing and pylon, thereby reducing the drag of hub fairing systems. Under the integrated effects of with above-mentioned factors, the interference effect of blade wake reducing the drag of hub fairing systems during the increased wind speeds. The drag of optimized model is still lower than base model in the interference of rotor wake, which reveals that the optimized technique which is to reshape the shaft fairing and pylon is effective in the presence of rotor wake. 


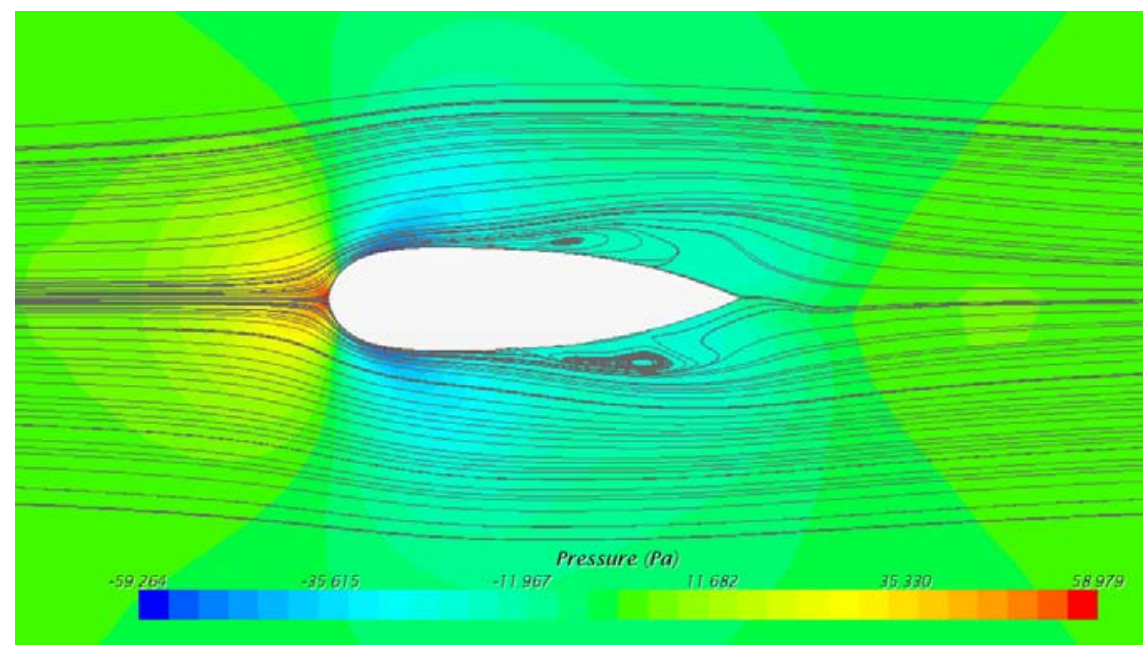

a)

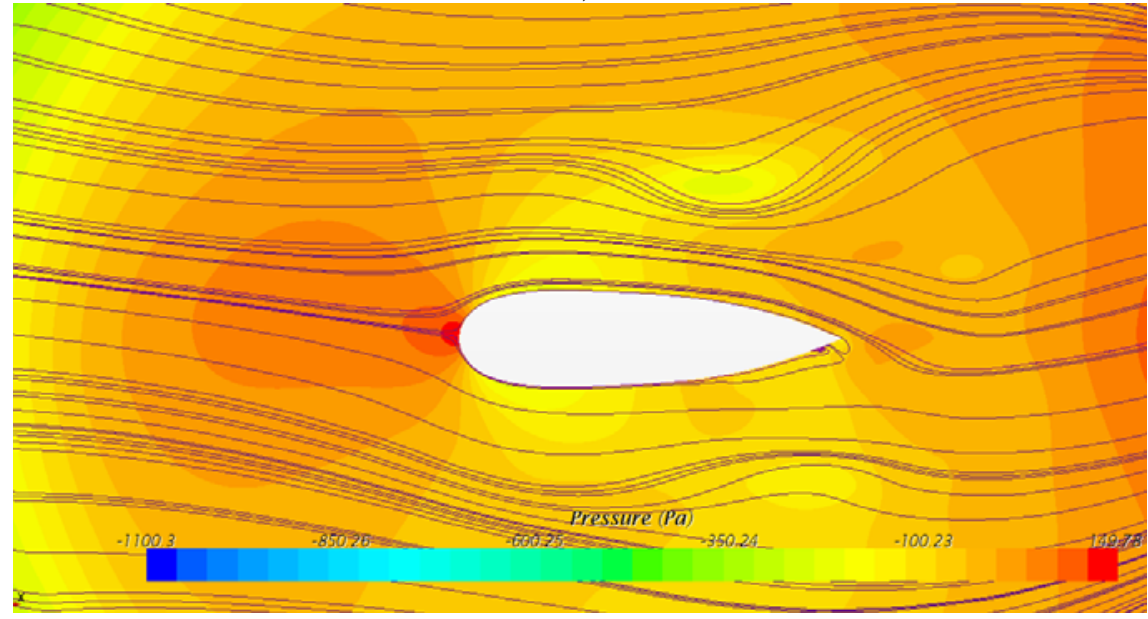

b)

Fig 7. Comparison of flow streamline on the horizontal cross section of shaft fairing of optimized model without the influence of rotor wake a), with the influence of rotor wake b) at $10 \mathrm{~m} / \mathrm{s}$ speed.

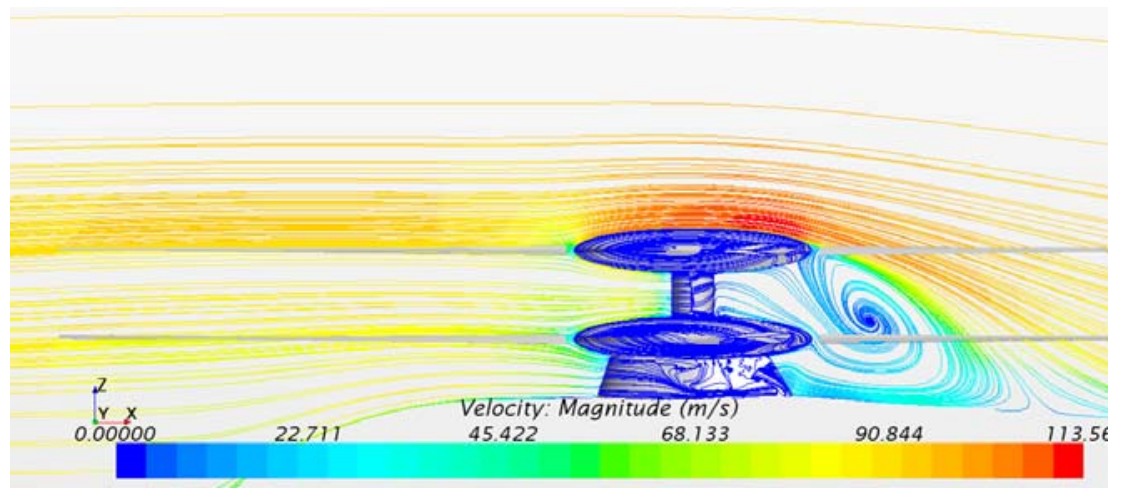

Fig 8. Flow streamline on the longitudinal cross section of baseline model with the influence of rotor wake at $90 \mathrm{~m} / \mathrm{s}$ speed. 


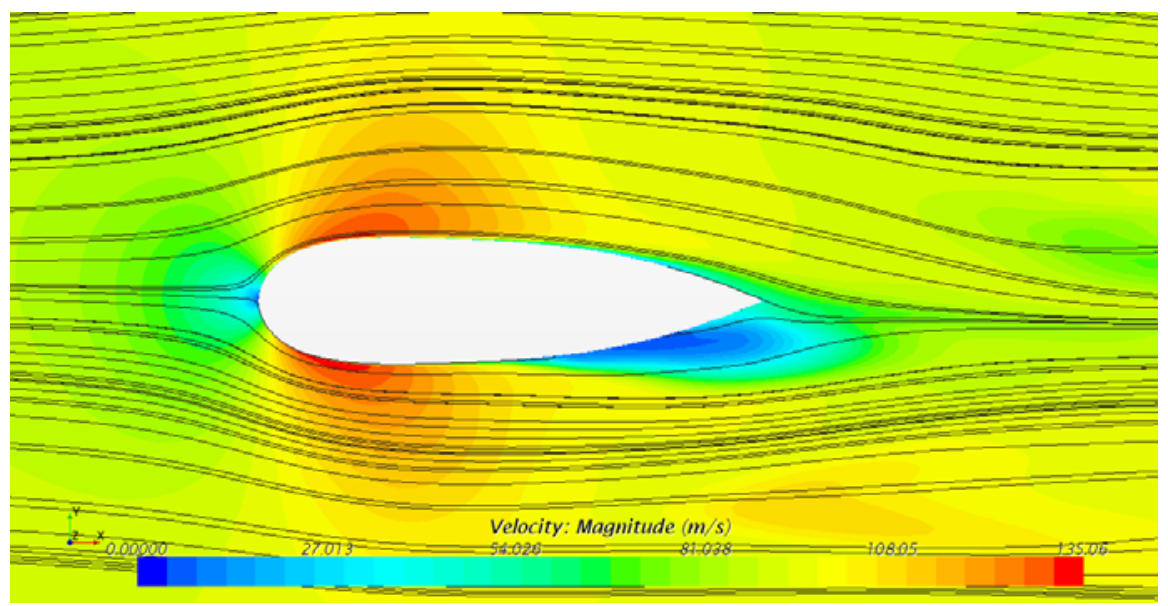

a)

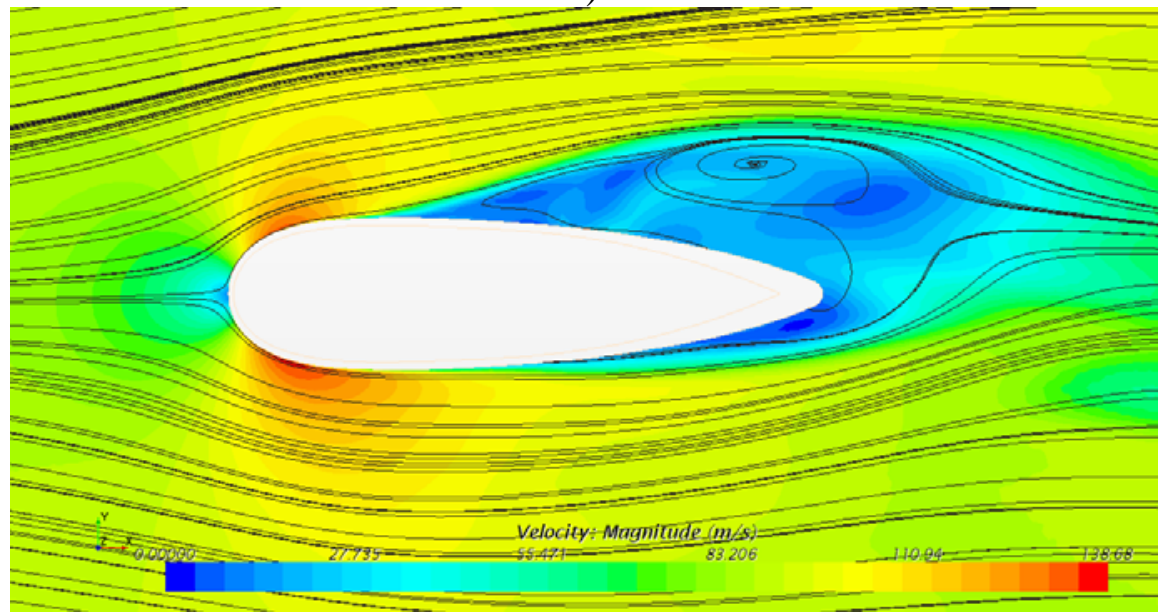

b)

Fig 9. Flow streamline on the horizontal cross section of shaft fairing a) and pylon b) of optimized model affected by the rotor wake at $90 \mathrm{~m} / \mathrm{s}$ speed.

\section{Conclusion}

Computational effort has been applied to obtain the interference effect of coaxial rigid rotor blade wake on hub fairing systems. The investigation here has yielded these conclusions:

1. The presence of the rotor wake increases the hub system drag in low speed range, but the growth by the disruption is declining with the speed increase. The additional rotor wake remarkably increases the hub system drag in low speed range, and makes the hub system drag slightly reduction at higher speed.

2. The swirl and downwash component of rotor wake have significant interference effect on each parts of hub fairing system. With the increase of wind speed, interference effects have been altered by the movement of rotor wake.

3. The downwash component occupies a dominant part of rotor wake in low speed flight, resulting in a move upward of the stagnation point near the leading edge of hub fairing, and then increases stagnation pressure and greater adverse pressure gradient. These factors introduce a sharp increase in the drag of hub fairing, particularly for the upper hub fairing. As the wind speed increases, the rotor wake moves upward and backward with the relative decrease of downwash component, resulting in mitigation in the amount of growth of hub fairing drag

4. Under low wind speed range, the swirl component of rotor wake disturb the shaft and pylon started from the upstream, increase the angle of attack and the stagnation pressure on their horizontal cross section, resulting in increased flow separation of shaft and pylon and interference drag in hub fairings. As the wind speed increases, the rotor wake moves upward and backward, the swirl 
component of rotor wake mainly mitigate the flow separation on the downstream of horizontal cross-section of shaft fairing and pylon, thereby reducing the overall drag of hub fairing systems.

5. The drag of optimized model is still lower than base model in the interference of rotor wake, which reveals that the optimized technique which is to reshape the shaft fairing and pylon is effective in the presence of rotor wake.

\section{References}

[1] Rudell et al. Advancing Blade Concept (ABC) Technology Demonstrator report: USAAVRADCOM-tr-81-D-5, United States Army Research Laboratory, and April 1981. Size: 11 MB. Accessed: 10 March 2012.

[2] Goodier, Rob (September 20, 2010). "Inside Sikorsky's Speed-Record-Breaking Helicopter Technology". Popular Mechanics. Retrieved 22 September 2010.

[3] Croft, John. Hyper Helos: Prototypes coming off the drawing board and into the race, Flightglobal.com 3 July 2008. Accessed: 9 March 2012.

[4] Bagai, Ashish. "Sikorsky XH-59A ABC (S-69)." airliners.net, March 29, 2011. Retrieved: June 8, 2011.

[5] Chandler, Jay. "Advanced rotor designs break conventional helicopter speed restrictions (page 1) Archived July 18, 2013, at the Wayback Machine. " Page 2 Archived July 18, 2013, at the Wayback Machine. Page 3 Archived July 18, 2013, at the Wayback Machine. ProPilotMag, September 2012. Accessed: 10 May 2014. Archive 1 Archive 2

[6] Balch, D.T. and Weiner, S., “1/5 Scale ABC Hub Fairing Drag Test - Final Report,” Sikorsky Engineering Report, SER-69063, NASA2-10215, March 5, 1980

[7] Brian E. Wake, Ebru Hagen, Stuart S. Ochs and Claude G. Matalanis, “Assessment of Helicopter Hub Drag Prediction with an Unstructured Flow Solver,"Presented at the American Helicopter Society 65th Annual Forum, Grapevine, Texas, and May 27-29, 2009.

[8] He Long, Wang Chang, Tang Min, "Drag characteristic test for hub of coaxial-rigid-rotor helicopter," Journal of Nanjing University of Aeronautics \& Astronautics, 2016, 48 (4):L530-535.

[9] Patrick O. Bowles, Mathew Thomas, Byung-Young Min, Derek Geiger, Barbara B. Botros, Claude G. Matalanis, Brian E. Wake, "Experimental Investigation of Passive and Active Flow Control for X2 Technology ${ }^{\mathrm{TM}}$ Hub and Fuselage Drag Reduction,” Presented at the AHS 72nd Annual Forum, West Palm Beach, Florida, USA, May 17-19, 2016. 